\title{
Devices for Testing Effectiveness of Electronic Equipment Protection against Electromagnetic Pulse (EMP)
}

\author{
Vladimir Gurevich, Ph.D. \\ Central Electrical Laboratory Israel Electric Corp. Haifa, Israel \\ *Corresponding Author: Vladimir Gurevich, Central Electrical Laboratory Israel Electric Corp. Haifa, \\ Israel
}

\begin{abstract}
Due to recent intensive development of methods and means of protection of electric power system equipment against High-altitude Electromagnetic Pulse (HEMP), both the assessment of the existing unprotected equipment vulnerability and the evaluation of the means for increasing resilience become particularly relevant. This article reviews the devices offered on the market to assess the different aspects of the effectiveness of equipment protection against the electromagnetic pulse and presents recommendations for choosing the right device.
\end{abstract}

Keywords: Testing Devices, Shielding Effectiveness, VNA, EFT, Electromagnetic Pulse, HEMP

\section{INTRODUCTION}

Recently, the challenge of the electric power system equipment protection against the high-altitude electromagnetic pulse (HEMP) has become very relevant due to the significant increase in power industry vulnerability and exposure to HEMP, and accounts for the ever-growing use of microelectronic and microprocessor systems in power generation, transmission and distribution processes. The military institutions of many developed countries have a tendency to intensively develop the means and methods of remote damage of microelectronic and microprocessor systems to have the ability to destroy the infrastructures of enemy countries during possible future conflicts [1].

Today, measures designed for electric power system equipment protection against HEMP are also intensively developed [2]. However, since the power industry is a non-military sector, it is hardly possible to use proven and tested military means of protection in this industry as they are rather expensive. Therefore, we need to compromise and find solutions to develop new and more affordable means of protection for this industry. In this context, the testing of the effectiveness of such new and previously not used means of protection is especially relevant. The article contains the review of the means designed for testing of the effectiveness of the electric equipment protection against HEMP available on the market and presents the recommendations for choosing the right device.

\section{Testing of Electric EQuipMent Resilience to Direcn IMPACT OF EMP EleCtrical FIELD (E1 - COMPONENT)}

It is known that upon the high-altitude explosion of a nuclear device (40km-400km above the ground) the pulse electric field up to $50 \mathrm{kV} / \mathrm{m}$ (the so-called E1 component of HEMP) appears near the ground surface and spans over a large territory. There are special simulators designed for testing the electric equipment sustainability to E1 component. They can be categorized as follows: compact laboratory and large fixed.

The fixed HEMP test-bed usually consists of the concrete base with bonded-in metal mesh acting as the first electrode, and the overhead metal mesh located 10-15 meters above the concrete base which acts as the second electrode. A high-voltage pulse applied between these two electrodes is sent from the output of a special type of generator. Usually it is a Marx Generator built on a set of high-voltage capacitors and switching spark gaps, controlled by pressed air and immersed into the large oil-bath or an $\mathrm{SF}_{6}$ gas reservoir. The size of such a test-bed makes it suitable for testing rather large items, such as tanks and aircraft. 

(EMP)

Many countries have large test-beds generating the HEMP with required values. The common technical parameters of such beds are mentioned in IEC standard [3]. For example, there are several such test-beds in the USA (TORUS, ALECS, ARES, WSMR, ATLAS, VPBW, etc.) and two in Russia:

- complex ALLUR in the High-Voltage Scientific-Research Center of Federal State Unitary Enterprise Russian National Electric Technical Institute (Istra, Moscow Region)

- research center in the Federal State Unitary Enterprise 12th Central Scientific-Research Institute of the Ministry of Defence of Russian Federation, Sergiyev Posad.

Many European countries and also Israel (in the Rafael Advanced Defense Systems, Haifa)has a large test-bed

Ukraine also has a similar test-bed -located at "Molniya" Research and Design Institute, Kharkiv.

Compact laboratory simulators are manufactured by several companies and are available on the market, see Fig. 1.
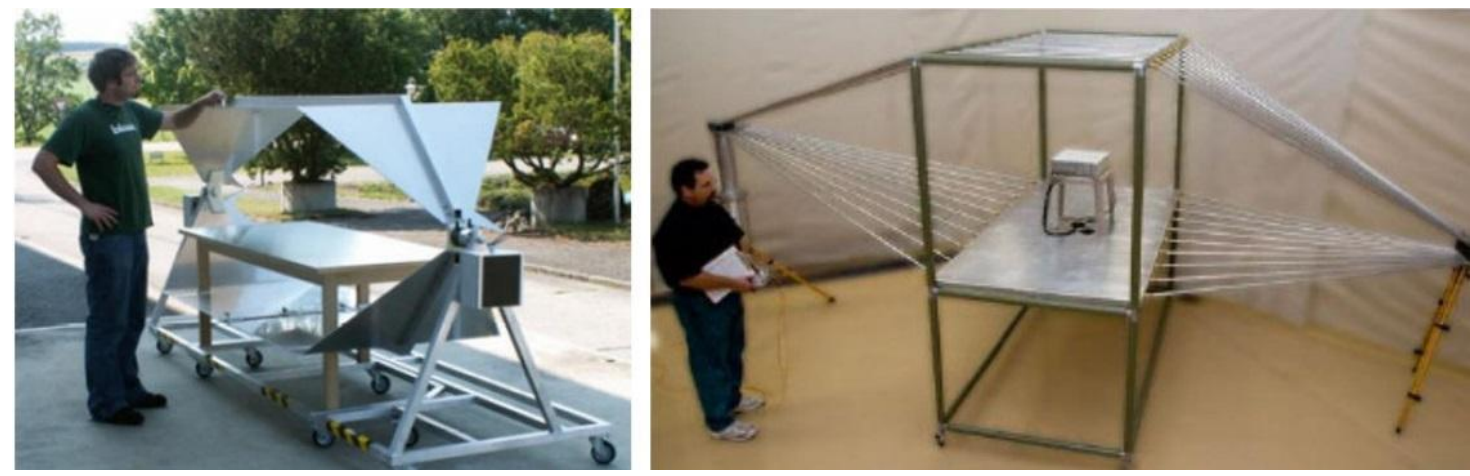

Fig1. Compact test-beds for testing electronic apparatus sustainability to HEMP. a-Montena Technology, 6 Applied Physical Electronics

The parameters of pulses generated by these compact beds fully correspond to the requirements of MIL-STD-188-125-1 [4] and MIL-STD-461F [5] standards. However, such beds are rather expensive (over $\$ 100 \mathrm{k}$ ). In addition, they are designed for testing smaller items, such as standalone digital protection relays (DPR). However, as we see from [6], since in the power industry the electronic devices (particularly DPRs) are used within the large distributed systems consisting of numerous long cables (acting as antennas absorbing the HEMP energy), the testing of individual devices, without due regard to their numerous interconnections with other devices, is hardly reasonable. While such testing of individual devices could be interesting for developers, generally speaking, it is not useful for the power industry. Besides, such individual devices are mounted inside the metal cabinets. It means that the test should be combined (device + cabinet), instead of focusing on the single device only. All the above mentioned leads to the conclusion that it is unreasonable to purchase very expensive compact laboratory test-beds for testing individual types of electronic equipment for the sustainability to HEMP. The testing of the set of equipment on fixed test-beds can be much more effective [7].

\section{DEVICES FOR HEMP FILTERS TESTING}

The feasibility of application of special HEMP filters offered by numerous manufacturers is uncertain [7]. Components such as dismountable ferrite beads and chokes can be widely used for the current pulse amplitude limitation within the electric circuits suffering from the HEMP impact. However, it is referred to the very different operating currents with significantly different frequencies (from DC to high-frequency current) and amplitudes (from milliamps to hundreds of Amperes).

Electromagnetic properties of ferrite beads and chokes change significantly upon the operating current frequency and amplitude change. Also, they essentially depend on the analogous parameters of the noise to be eliminated by such beads [8].

Thus, the effectiveness of ferrite beads (more correctly, of bead sets) and chokes must be tested under the conditions closest to the real-life operation, as well as to the real parameters of the impacting electromagnetic pulse. 

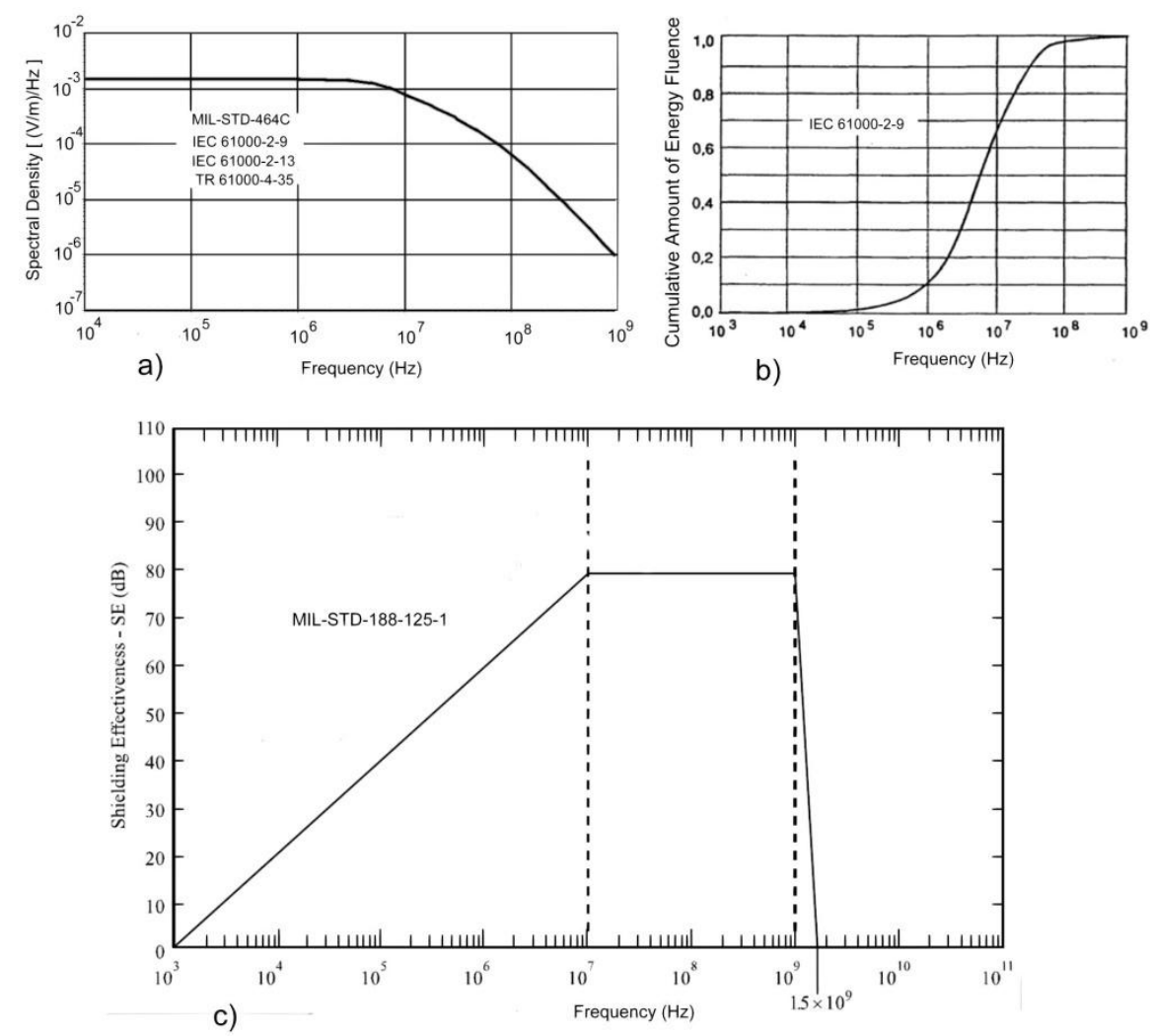

Fig2. Determination of HEMP frequency range in different standards

The effectiveness of ferrite beads is determined by their ability to attenuate the noise signal within the certain frequency range. While at this situation the noise is presented by HEMP, the first stage should include the determination of the frequency range that the bead testing equipment must operate within. Then, this frequency range must be used to determine the test equipment corresponding to this parameter. Evaluation of different standards shows, see Fig. 2, that the required frequency range for the test equipment can be selected from several hundreds of $\mathrm{kHz}$ to $1 \mathrm{GHz}$.

It is known that insertion loss (noise attenuation degree) is the basic characteristic of the electromagnetic filter. Within the system of so-called S-parameters (scattering parameters), the filters are characterized by direct and backward transmission coefficients, such as $S_{21}$ and $S_{12}$. There are special devices used for measurement of these parameters - Vector Network Analyzers (VNAs). As a rule, VNAs have two ports (signal source and signal receiver) and are designed for measuring one set (one-patch) of S-parameters $\left(S_{21}\right.$ and $\left.S_{12}\right)$, or two (two-patch) sets of them $\left(S_{22}\right.$ and $S_{11}$ in addition to the previous set). Additional S-parameters $\left(S_{22}\right.$ and $\left.S_{11}\right)$ determine the signal reflection degree and are not peculiar to the filters.

During the test, the filter is connected between two VNA ports and filter effectiveness is determined by the signal difference (in $\mathrm{dB}$ ) on VNA ports over the whole selected frequency range.

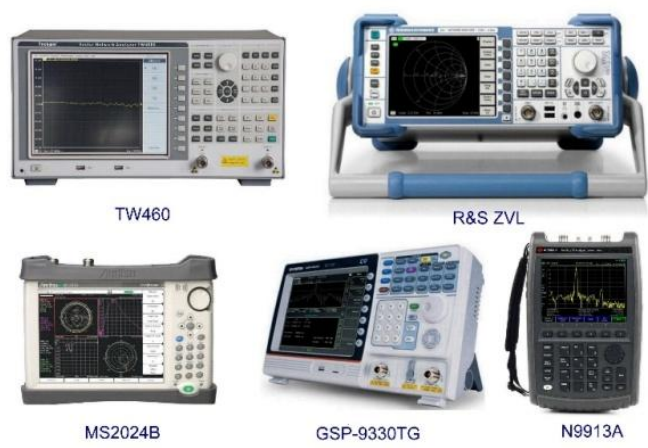

Fig3. Several types of standalone VNAs available on the market. Top - fixed devices with numerous additional features and large display, bottom - compact mobile devices

International Journal of Research Studies in Electrical and Electronics Engineering (IJRSEEE) Page | 8 
Devices for Testing Effectiveness of Electronic Equipment Protection against Electromagnetic Pulse (EMP)

Basically, it is the diagram demonstrating the filter inserted losses as a function of the input signal frequency. The dynamic range characterizing the signal attenuation ratio to be measured by the device is another most important parameter of VNA. As a rule, all VNAs have a dynamic range of $100 \mathrm{~dB}-$ $120 \mathrm{~dB}$, minimum.

Therefore, the basic requirements to HEMP filters test devices are as follows:

- Implementable features $-\mathrm{S}_{21}$ and $\mathrm{S}_{12}$.

- Frequency range ftom $100 \mathrm{kHz}-300 \mathrm{kHz}$ up to $1 \mathrm{GHz}$.

- Dynamic range - at least 100dB.

All other numerous VNA parameters, usually indicated by the manufacturers, are not critical for the desired goal.

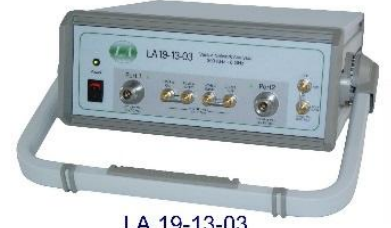

LA 19-13-03

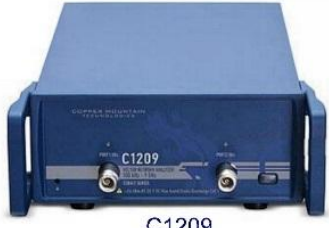

C1209

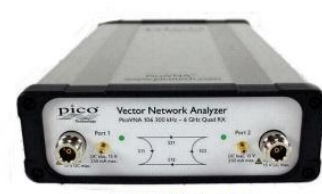

PicoVNA 106
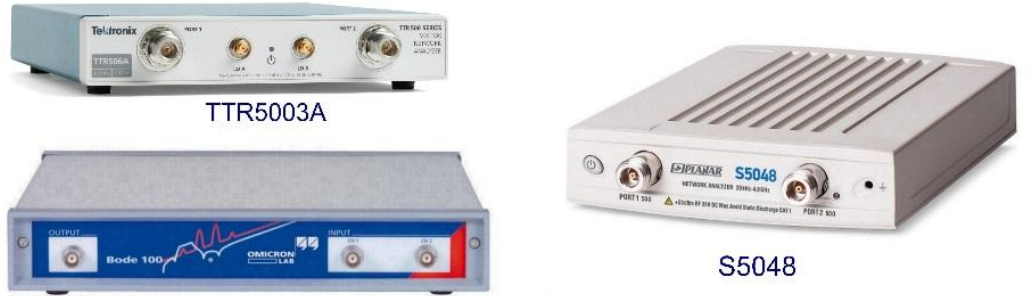

S5048

Bode 100

Fig4. VNAs w/o displays designed to be connected to PC

Table 1. The cost of the most common types of VNAs

\begin{tabular}{|c|c|c|}
\hline TypeVNA (Manufacturer) & Frequency Range & Cost \\
\hline ZNL3 (Rohde \& Schwarz) & $5 \mathrm{kHz}-3 \mathrm{GHz}$ & $\$ 20.000$ \\
\hline C1209 (Cooper Mountain Techn.) & $100 \mathrm{kHz}-9 \mathrm{GHz}$ & $\$ 22.000$ \\
\hline LA19-13-03 (LA Techniques Ltd.) & $300 \mathrm{kHz}-8 \mathrm{GHz}$ & $\$ 10.600$ \\
\hline MS2024B (Anritsu) & $50 \mathrm{kHz}-4 \mathrm{GHz}$ & $\$ 10.450$ \\
\hline N9913A (Keysight Technology) & $30 \mathrm{kHz}-4 \mathrm{GHz}$ & $\$ 15.000$ \\
\hline TW4600A (Techwin Industry Co.) & $100 \mathrm{kHz}-3 \mathrm{GHz}$ & $\$ 9.300$ \\
\hline GSP-9330TG (GW Instek) & $9 \mathrm{kHz}-3.3 \mathrm{GHz}$ & $\$ 7.000$ \\
\hline TTR5003A (Tektronix) & $100 \mathrm{kHz}-6 \mathrm{GHz}$ & $\$ 9.000$ \\
\hline Planar TR5048 (Cooper Mountain Techn.) & $20 \mathrm{kHz}-4.8 \mathrm{GHz}$ & $\$ 7.800$ \\
\hline PicoVNA 106 (Picotech) & $300 \mathrm{kHz}-6 \mathrm{GHz}$ & $\$ 6.000$ \\
\hline VNAuhf (Array Solutions) & $5 \mathrm{kHz}-1.2 \mathrm{GHz}$ & $\$ 1.250$ \\
\hline USB-SA44B + USB-TG44A (Signal Hound) & $10 \mathrm{~Hz}-4.4 \mathrm{GHz}$ & $\$ 1.750$ \\
\hline Planar TR1300/1 (Cooper Mountain Techn.) & $300 \mathrm{kHz}-1.3 \mathrm{GHz}$ & $\$ 2.900$ \\
\hline VNA 6050-5100 (AEA Technology) & $100 \mathrm{kHz}-1 \mathrm{GHz}$ & $\$ 2.300$ \\
\hline
\end{tabular}

In reality, it is rather difficult to choose one particular device corresponding to all mentioned requirements due to the widest breadth of such devices on the market, see Fig. 3 and Fig. 4, with significantly different technical functions and costs, see Table 1.

Basically, the increase in upper edge frequency leads to sharp increase in cost, so only the models with minimal upper edge frequency were chosen for the analysis.

However, it transpired that there is even more. Many manufacturers of spectrum analyzers equip their devices with integrated tracking generators, allowing the simple spectrum analyzer to be used as VNAs. Also, some of them offer sets consisting of two separate devices: spectrum analyzer and tracking generator, see Fig. 5. Two small such boxes should be interconnected and then connected to a PC in order to use its display. Thus, we get the very compact, simple and cheap device.

International Journal of Research Studies in Electrical and Electronics Engineering (IJRSEEE) Page 9 


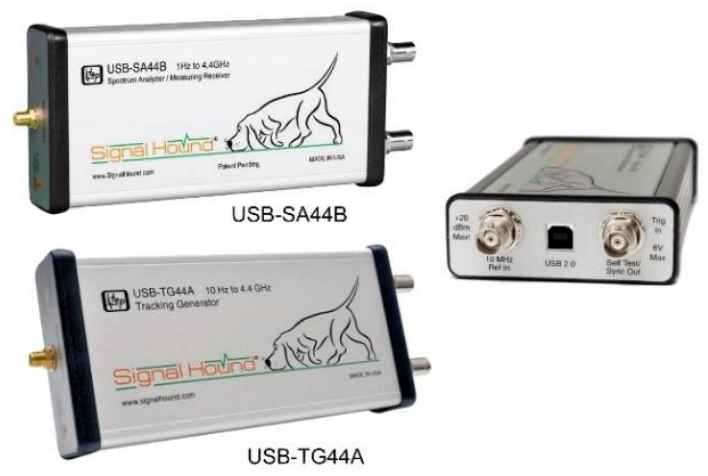

Fig5. Simple and cheap combined VNA - spectrum analyzer (USB-SA44B) c/w tracking generator (USB$T G 44 A)$

Based on the value for money parameter for this particular application, two VNAs, see Fig. 6, can be selected (due to their satisfactory parameters and minimal cost) from the wide variety of offers available on the market.
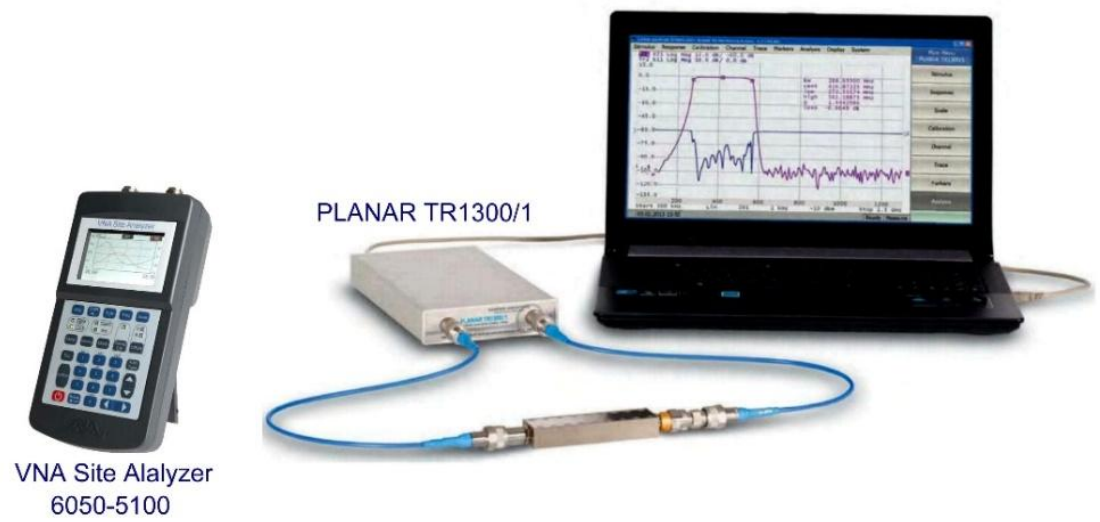

Fig6. Two VNAs with the best value for money parameters for the particular application

Therefore, it is the decision of the user which one to choose - absolutely standalone compact PCenabled unit with its own display or the device designed as a supplement to a PC.

Also, along with VNA, the set for VNA calibration must be purchased. In the simplest case, such a calibration set consists of three connectors: open (without additional inner components), shortcircuited, and 50Ohm (internal resistance) connector.

\section{Devices Designed For Evaluation of Buildings, Rooms and Cabinets Shielding EFFECTIVENESS}

The devices of this type contain transmitters, receivers and a set of antennas for different frequency ranges. Before using, such devices should be reset to zero. To do this, the receiver with the directed antenna should be installed near and opposite to the transmitter with the directed antenna. Then, the zero value attenuation should be reached while the transmitter and the receiver remain active, see Fig. 7.
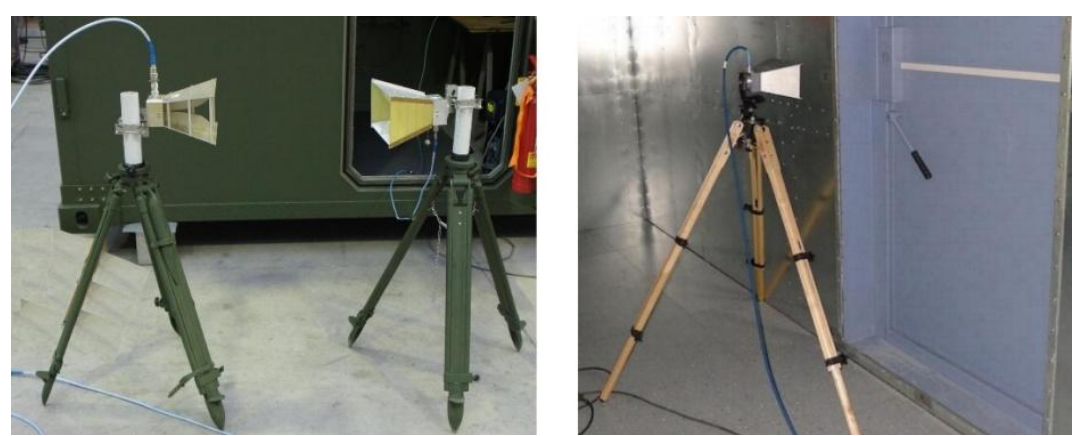

Fig7. Adjustment (resetting to zero) and usage of device for evaluation of shielding effectiveness

International Journal of Research Studies in Electrical and Electronics Engineering (IJRSEEE) Page | 10 

(EMP)

Subsequently, the transmitter should be placed outside the protected facility, and the receiver should be placed in the same facility at the distance equal to the distance used upon resetting to zero. Then, the difference between the sent and the received signal should be used for evaluating the facility shielding effectiveness (i.e. signal attenuation rate).

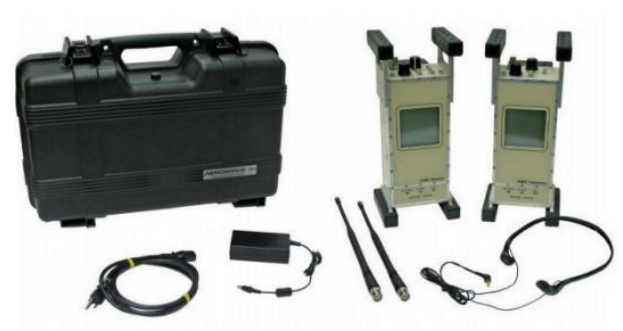

PAMS

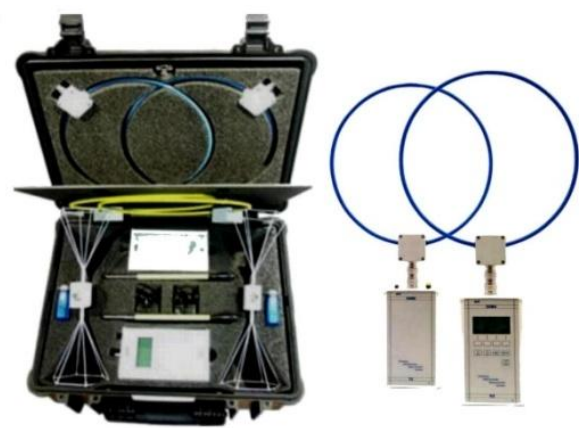

SEMS

Fig8. Devices designed for evaluation of shielding effectiveness available on the market

As for such devices, the market situation is totally different from the above VNAs. As it happened, the market offers only a very limited range of them, see Fig. 8.

Evaluation of the frequency range showed that only one of the devices (SEMS), more or less corresponds to the specific application. However, it is not $100 \%$ suitable because its frequency range $(10 \mathrm{kHz}-300 \mathrm{MHz})$ does not reach $1 \mathrm{GHz}$. However, that was the best option that was available. The device costs is $\$ 16.000$.

Some publications state that VNAs can be used for the shielding effectiveness evaluation also, see Fig. 9. They suggest to connect the transmitter and receiver antennas to corresponding VNA ports and make the same adjustment (resetting to zero) procedure as for the special device.

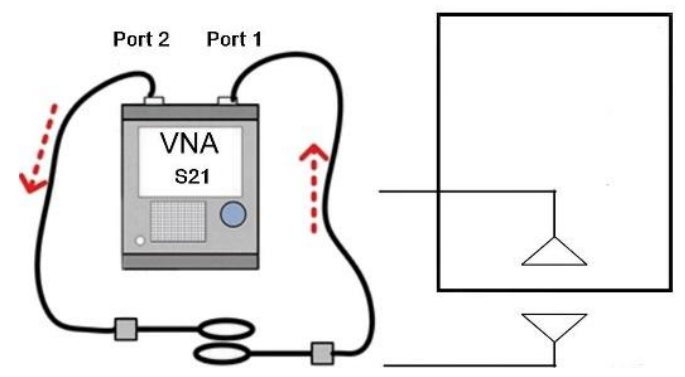

Fig9. Using VNA for evaluation of shielding effectiveness

Probably it is really possible and efficient. If it is true, the market offers a lot of different VNAs suitable for every application, and less expensive as compared to the special standalone device. However, there is a minor problem related to the necessity to lead the receiver antenna wire out of the protected area according to the standard requirements.

In any case, it should be noted that such VNA application not be tested me.

\section{Pulse Voltage Generator}

Table 2. Maximum amplitude of 5/50 nanoseconds output voltage pulse of EFT generators (IEC 61000-4-4) available in the market.

\begin{tabular}{|l|l|c|}
\hline Type of EFT generator & Manufacturer & Maximal pulse magnitude \\
\hline PEFT 8010 & Haefely EMC Technology & 7.3 \\
\hline NSG 2025* & TESEQ & 8 \\
\hline J0101031/3* & Kentech Instruments Ltd. & 8 \\
\hline KeyTek ECAT E421* & Thermo Electron Corp. & 4.8 \\
\hline FNS-AX3-A16B & NoiseKen Laboratory Co. & 7 \\
\hline EFT 500N8 & EMTEST & 5 \\
\hline TRA3000 & EMC Partner & \\
\hline
\end{tabular}

International Journal of Research Studies in Electrical and Electronics Engineering (IJRSEEE) Page | 11 
Devices for Testing Effectiveness of Electronic Equipment Protection against Electromagnetic Pulse (EMP)

\begin{tabular}{|l|l|c|}
\hline EFT 6501 & Schaffner & 4.4 \\
\hline EFT-4060B & $\begin{array}{l}\text { Shanghai Yi } \\
\text { PaiElectronmagneticTechn. }\end{array}$ & 6.6 \\
\hline EFT500 & Suzhou 3Ctest Electronic Co. & 5 \\
\hline AXOS8 & Hipotronics & 5 \\
\hline
\end{tabular}

obsolete* $^{*}$

By directly applying the test voltage pulse to the tested equipment means the so-called Electrical Fast Transient (EFT) pulse with parameters (except test voltage amplitude) and test procedure is welldescribed in Standard IEC 61000-4-4, see Fig. 10. The amplitude of HEMP test voltage (designated as "special") is denoted by "X" in Table 1 of this standard and corresponds to E8 and E9 levels. The research [7] demonstrated that under the typical power industry conditions, the amplitude of this pulse should be equal to $8 \mathrm{kV}$.Previously, EFT generators with a required level of output voltage $8 \mathrm{kV}$ were manufactured by TESEQ, Kentech Instruments Ltd., and Thermo Electron Corp. (see Table 2), and were built on triggered vacuum gaps generating test pulses. With the advent of solid-state switching elements such as IGBT-transistors, triggered vacuum gap generators were divested by all three companies, as the pulses generated by the transistors were much more stable and "correct" compared to pulses generated by the vacuum gaps. Unfortunately, improved stability of generated pulses was accompanied by the decrease of their amplitude.

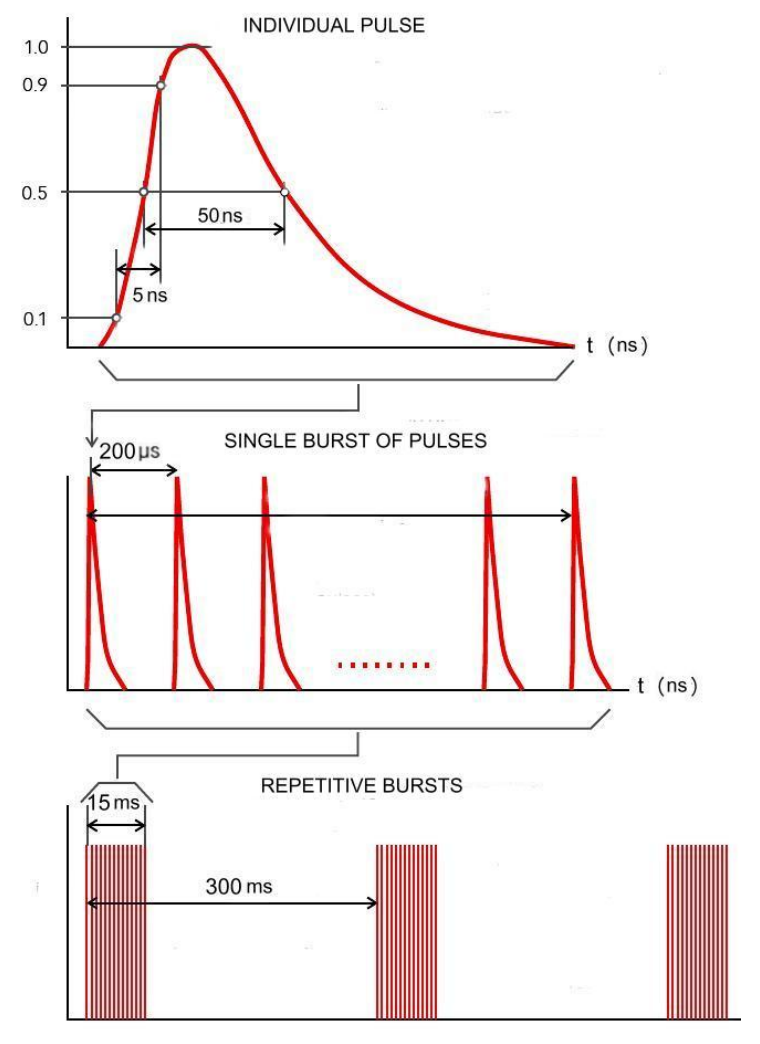

Fig10. Electrical Fast Transient (EFT) - fast pulse (IEC 61000-4-4)

Our analysis shows that EFT generators presently available on the market do not fully satisfy the requirements of pulse amplitude standards $(8 \mathrm{kV})$.
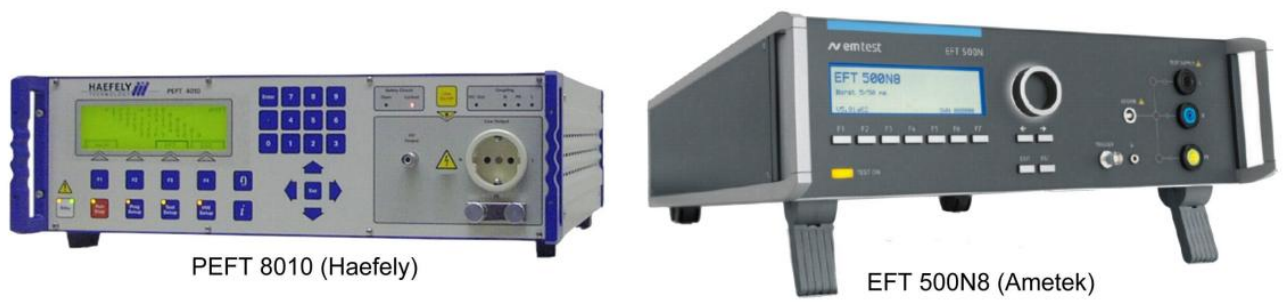

Fig11. EFT-generators with the parameters best matched to required pulse amplitude parameters 


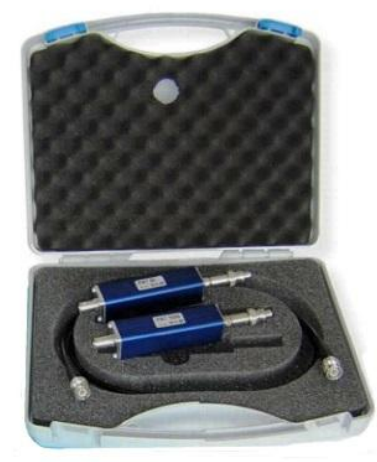

PAT50, PAT1000

(Haefely)

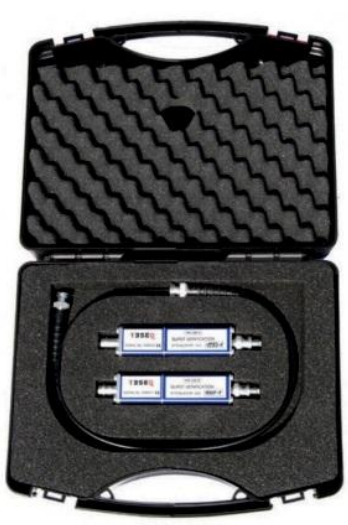

CAS 3025

(Teseq AG)

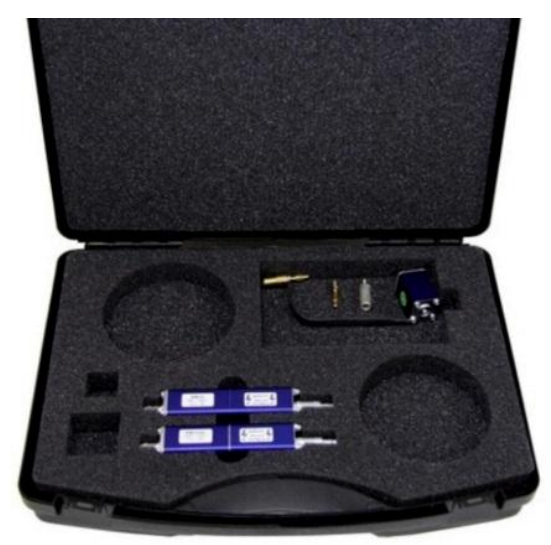

KW50, KW1000

(Ametek)

Fig12. Calibration sets for EFT-generators

Generator type PEFT 8010 (Haefely EMC Technology) and EFT 500N8 (Ametek) best match the required pulse amplitude value. They consist of integral filters (Coupling-Decoupling Network $\mathrm{CDN}$ ) protecting the supply network from the penetration of pulses generated by the device, see Fig. 11. They cost $\$ 25-30 \mathrm{k}$.

Similarly, to all the above devices, the generators must be calibrated periodically. For this purpose, sets of special high voltage noninductive dividers of $50 \mathrm{Ohms}$ and $1000 \mathrm{Ohms}$, receiving the generator output pulse are provided, see Fig 12. The amplitude and length of such a pulse (with corresponding dividing ratio) are measured by the oscilloscope.

\section{CONCLUSION}

The above review of devices available on the market and recommendations for choosing the right device can be helpful to the employers of power systems. They can make both the evaluation of the vulnerability of existing unprotected equipment, and the assessment of the effectiveness of means and methods aimed to protect such equipment against HEMP much more easy and simple.

\section{REFERENCES}

[1] Gurevich, V., Cyber and Electromagnetic Threats in Modern Relay Protection. - Taylor \& Francis Group, Boca Raton, 2015, 205 p.

[2] Gurevich, V., Protection of Substation Critical Equipment against Intentional Electromagnetic Threats. Wiley, London, 2017, $240 \mathrm{p}$.

[3] IEC 61000-4-32 Electromagnetic compatibility (EMC) - Part 4-32: Testing and measurement techniques High-altitude electromagnetic pulse (HEMP) simulator compendium.

[4] MIL-STD-188-125-1 High -Altitude Electromagnetic Pulse (HEMP) Protection for Ground Based C41 Facilities Performing Critical. Time-Urgent Mission. Part 1 Fixed Facilities, 2005.

[5] MIL-STD-461F Requirements for the Control of Electromagnetic Interference Characteristics of Subsystems and Equipment, 2007.

[6] Gurevich, V. Problems in Testing Digital Protective Relays for Immunity to Intentional Destructive Electromagnetic Impacts. - Global Journal of Advanced Research, 2014, Vol.1, Issue 2, pp. 159-173.

[7] Gurevich, V. Main Principles of Electromagnetic Pulse Immunity Test Methods for Power System Electronics. - International Journal of Research Studies in Electrical and Electronics Engineering (IJRSEEE) Vol. 2, Issue 2, 2016, pp. 1-8

[8] Gurevich, V., The problem of correct choice of ferrite beads, Electrical Engineering \& Electromechanics, 2016, No. 2, pp. 71-73. 


\section{AUTHOR'S BIOGRAPHY}

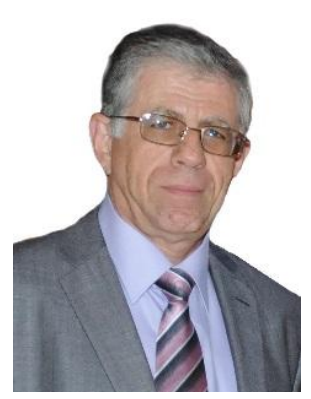

Vladimir I. Gurevich, was born in Kharkov, Ukraine, in 1956. He received an M.S.E.E. degree (1978) at the Kharkov Technical University, named after P. Vasilenko, and a Ph.D. degree (1986) at Kharkov National Polytechnic University.

His employment experience includes: teacher, assistant professor and associate professor at Kharkov Technical University, and chief engineer and director of Inventor, Ltd.

In 1994, he arrived in Israel and works today at Israel Electric Corp. as a Senior specialist and Head of section of the Central Electric Laboratory. He is the author of more than 200 professional papers and 15 books and holder of nearly 120 patents in the field of electrical engineering and power electronics. In 2006 he was Honorable Professor with the Kharkov Technical University.

Citation: Vladimir Gurevich (2017). Devices for Testing Effectiveness of Electronic Equipment Protection against Electromagnetic Pulse (EMP), International Journal of Research Studies in Electrical and Electronics Engineering (IJRSEEE), 3(3), pp.6-14, DOI: http://dx.doi.org/10.20431/2454-9436.0303002.

Copyright: (C) 2017 Vladimir Gurevich. This is an open-access article distributed under the terms of the Creative Commons Attribution License, which permits unrestricted use, distribution, and reproduction in any medium, provided the original author and source are credited 